The principle applied to acquire the reso-

\title{
Nondestructive Acoustic Measurement of Firmness for Nectarines, Apricots, Plums, and Tomatoes
}

\author{
Noboru Muramatsu \\ Department of Breeding, National Institute of Fruit Science, Fujimoto 2-1, \\ Tsukuba, Ibaraki 305, Japan
}

Naoki Sakurai

Department of Environmental Studies, Faculty of Integrated Arts and Sciences, Hiroshima University, Higashi Hiroshima 739, Japan

Ryoichi Yamamoto

Laboratory of Biology, Tezukayama College, Nara 631, Japan

Donald J. Nevins

Vegetable Crops Department, University of California, Davis, CA 95616

Additional index words. sound velocity, sound frequency, fruit maturity, texture evaluation methods, Prunus persica, Prunus mume, Prunus salicina, Lycopersicon esculentum

Abstract. A nondestructive, acoustic method was applied to evaluate firmness of nectarines (Prunus persica Batch.), apricots (Prunus mume Sieb. et Succ.), plums (Prunus salicina Lindl.), and tomatoes (Lycopersicon esculentum Mill. 'Beiju'). Sound with frequencies from 200 to $2000 \mathrm{~Hz}$, generated by a miniature speaker attached to the fruit surface, was received by a small microphone attached to the opposite side. The signal was monitored by an oscilloscope. Sound frequency did not change during propagation in the fruit. However, as the microphone was moved along the circumference of the fruit, a phase shift in the received signal was observed. When the distance the microphone was displaced along the surface of the fruit corresponded to a shift of exactly one wavelength, the sound wavelength propagated within the fruit could be determined. The number of sound waves within the fruit over half its circumference was calculated as a function of this distance. Mature fruit propagated shorter wavelengths and consequently more sound waves than immature fruit, indicating that the sound velocity in the mature fruit was lower than in immature fruit. This relatively simple method for measuring lower frequency suggests that the sound velocity propagated through fruit can be determined without measuring the absolute velocity.

Measurement of fruit firmness is important for evaluating the quality of fruit texture. Fruit firmness has been measured by conventional destructive methods, for example, by MagnessTaylor methods (Abbott et al., 1992; Magness and Taylor, 1925), and, more recently, by stress-relaxation (Kojima et al., 1991, 1992, 1994; Sakurai and Nevins, 1992, 1993). The former method estimates the failure strength of the fruit, while the latter method provides

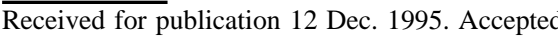
for publication 20 July 1996 . This work was supported, in part, by a Grant-in-Aid for Developmental Scientific Research (07556012) from the Ministry of Education, Science and Culture. N.M. wishes to express his gratitude to the staff at Hiroshima Univ. where this research was conducted and he also appreciates the support of Dr. Toshio Takahara and others at the Kuchinotsu Fruit Tree Research Station. Contribution No. 1044 of the National Institute of Fruit Science. The cost of publishing this pape was defrayed in part by the payment of page charges Under postal regulations, this paper therefore must be hereby marked advertisement solely to indicate this fact. values for viscous and elastic properties. The stress-relaxation method has a distinct advantage in measuring the viscoelastic properties of fruit (Cosgrove, 1986; Sakurai, 1991). In general, a representative sample of fruit is selected and evaluated for maturity and texture. Since each fruit varies in maturity at harvest, it would be expected that developmental patterns may vary during ripening after harvest. Any confirmation of the texture of individual fruit before shipping would provide a measure of ripeness and, as a result, would serve as the basis for a sorting strategy to deliver a more uniform product and reduce losses. A nondestructive method for assessing firmness would be a major advance in achieving quality control.

One simple, inexpensive, and nondestructive technique with potential for evaluating fruit firmness is the application of acoustical analysis. Three basic methods have been explored: 1) measurement of sound amplitude propagated through a fruit (Nybom, 1962), 2) resonant frequency (Abbott et al., 1992; Falk et al., 1958; Finney, 1970), and 3) sound velocity (Garrett and Furry, 1972). nance of material is as follows: a vibrator is used to induce a signal in the sample and the response of the material is measured. At each frequency, a specific, inherent peak is observed. This phenomenon was recognized as resonance, and the corresponding frequency as the resonant frequency. The resonant frequency was found to be closely related to the firmness of commodities and was an inherent property of the material

Abbott et al. (1992, 1994) reported that when an apple (Malus pumila Mill.) was subjected to 5 to $2,000 \mathrm{~Hz}$ input, there were several resonant frequencies detected, referred to as $\mathrm{f}_{1}, \mathrm{f}_{2}$, etc. from low to high frequency. They claimed that $f_{2}$ was most reproducible and that $\mathrm{mf}_{2}^{2}$ ( $\mathrm{m}$ is mass of fruit) served as a good index for fruit firmness. Cooke (1972) had earlier suggested that $\mathrm{m}^{2 / 3} \mathrm{f}^{2}$ was related to the elastic modulus.

Another method used to determine the resonant frequency is based on response to impact. Yamamoto et al. (1984a, 1984b, 1984c) reported that sound produced by striking fruit with a wooden hammer and perceived by a microphone, when analyzed by fast Fouriertransformation, could be used to calculate the resonance representing the inherent frequency of apple, watermelon (Citrullus lanatus Thunb.), and radish (Raphanus sativus L.) They compared the data obtained by conventional vibrating reed or compression methods with that obtained by impact, and claimed a high correlation. Armstrong et al. (1989) also applied a similar method to apples. The validity of an impact method was further confirmed with pumpkins (Curcubita pepo L.) and radishes (Chen et al., 1993), and with tomatoes and apples (De Baerdemaeker, 1989). All data correlated with those obtained by a penetrometer. Collectively, all these methods primarily employ resonant frequency in the analysis.

Measurement of sound velocity with ultrasonic waves has also been applied in the evaluation of solid materials (Krautkramer and Krautkramer, 1977). Mizrach et al. (1989) suggested that the velocity of ultrasonic sound could be used for ripeness classification in some fruits and vegetables. Self et al. (1994) showed that the ultrasonic velocity decreased in avocado flesh (Persea americana Mill.) as a function of ripening stage. Zebrowski (1992) also applied the ultrasonic method to measure the stiffness of stem and leaf sheaths of triticale $(\times$ Tritiosecale $)$. However, in most of these ultrasonic measurements, the attenuation coefficient was extremely high because of the amorphous nature of fruit and vegetable tissues (Mizrach et al., 1989; Sarker and Wolfe, 1983). Therefore, it is difficult to reliably measure the velocity of ultrasonic sound thorough these commodities. Generally, the attenuation coefficient decreases as the frequencies imposed on the material is lowered. Thus, relatively low frequencies (audible range) were applied for evaluation of texture of fruit. As a consequence, we demonstrated that changes in phase shift of transmitted sound could be readily determined and used as a firmness index. 
Oscilloscope

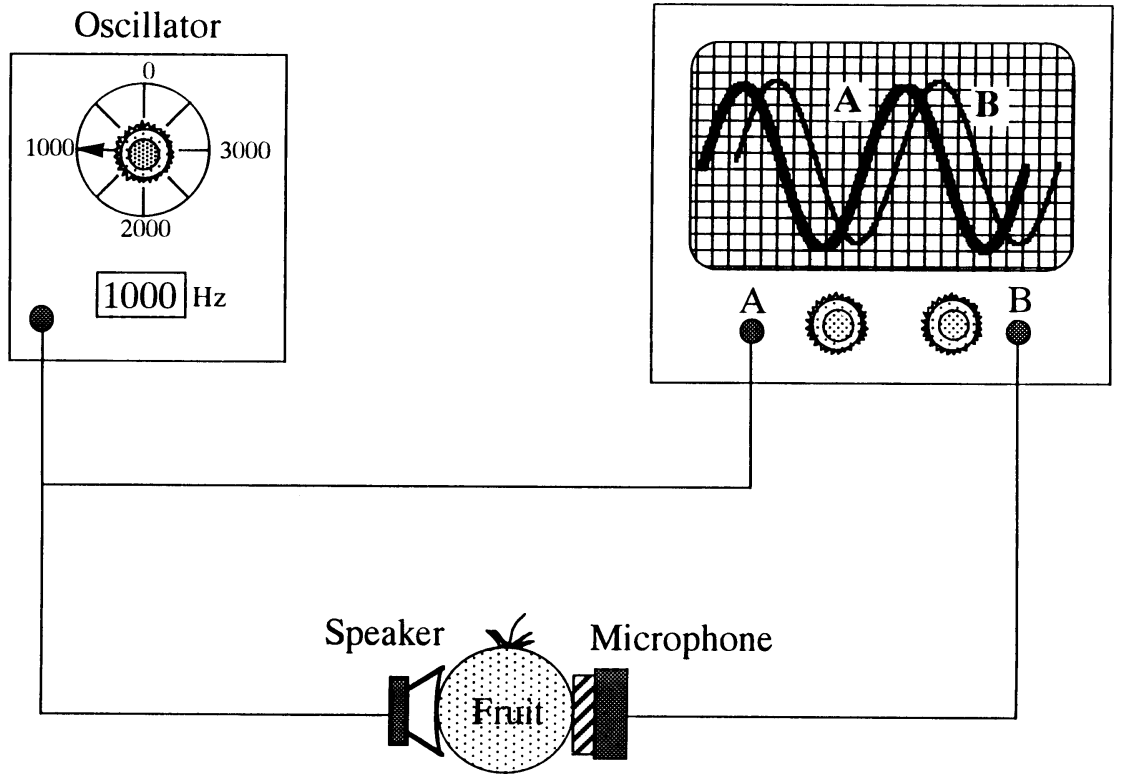

Fig. 1. Schematic diagram of experimental set-up for monitoring sound waves through a fruit. The fruit was placed on an adjustable stage. Sine-waves with differing frequencies were generated by an oscillator. The sound emitted by a small speaker attached to the fruit was received by a microphone attached to the opposite side of the fruit. Waves of emitted sound (Wave A) and received sound (Wave B) were simultaneously monitored by an oscilloscope. The phase shift of two waves was observed. Since the intensity of the received sound was much smaller than the emitted sound intensity, the intensity was amplified to be comparable to that of emitted sound. The frequency of the sound was increased stepwise from 200 to $2000 \mathrm{~Hz}$.

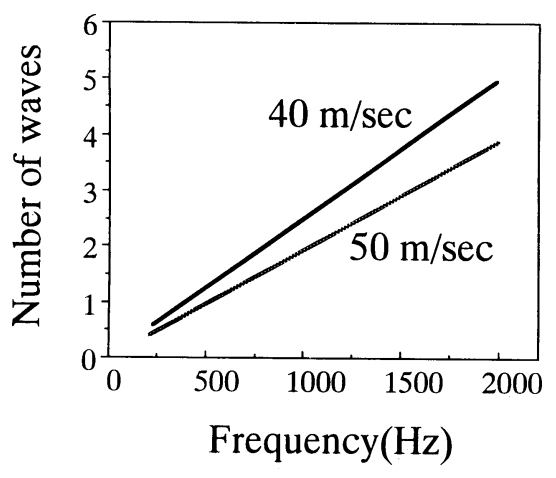

Fig. 2. Relationship between number of waves and sound frequency. When the sound is propagated through a distance of $10 \mathrm{~cm}$ with a velocity of 50 $\mathrm{m} \cdot \mathrm{s}^{-1}$ at $1000 \mathrm{~Hz}$, there must be two waves within the $10 \mathrm{~cm}$, because the wave length is 5 $\mathrm{cm}\left(50 \mathrm{~m} \cdot \mathrm{s}^{-1}\right.$ divided by $\left.1000 \mathrm{~s}\right)$. If the propagated sound does not change the velocity, at $2000 \mathrm{~Hz}$ there must be four waves in $10 \mathrm{~cm}$, because the wave length is $2.5 \mathrm{~cm}\left(50 \mathrm{~m} \cdot \mathrm{s}^{-1}\right.$ divided by $2000 \mathrm{~s}$ ). Therefore, the relation between number of waves in a fixed distance and sound frequency should be proportional. However, if the sound velocity is altered by the tissue, the relationship is also altered. If the velocity becomes $40 \mathrm{~m} \cdot \mathrm{s}^{-1}$, there must be five waves at $2000 \mathrm{~Hz}$ and 2.5 waves at $1000 \mathrm{~Hz}$ over a distance of $10 \mathrm{~cm}$.

\section{Materials and Methods}

Fruit. Nectarines, apricots, and plums were purchased from the local market. The fruit were immediately subjected to an initial acous-

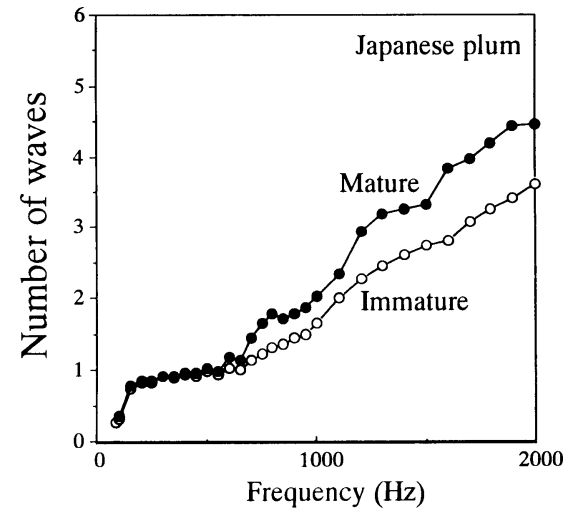

Fig. 3. Number of waves in mature and immature nectarine fruit. Wavelength in the nectarine fruit were measured by moving a microphone along the surface of nectarine fruit. Using the wavelength and measured distance of half the circumference of the fruit, the number of waves in the fruit was calculated. Data are means, and standard errors are shown $(n=4)$.

tic measurement. The same fruit were allowed to ripen at $5 \mathrm{C}$ for 2 to 3 weeks before subsequent measurements. For most sets of experiments, three tomato fruit were harvested at a mature-green stage. After acoustic measurements as described below, the same fruit were treated with ethylene at $10 \mu \mathrm{L} \cdot \mathrm{L}^{-1}$ for $24 \mathrm{~h}$ in a glass bottle, then stored at $5 \mathrm{C}$ for 3 days. Subsequent measurements were taken at a pink stage.

Acoustic measurements. In each case the fruit was placed on an adjustable stage. Monotonous sound from 200 to $2000 \mathrm{~Hz}(50 \mathrm{~Hz}$ intervals from 200 to $1000 \mathrm{~Hz}$, and $100 \mathrm{~Hz}$ intervals above $1000 \mathrm{~Hz}$ ) was generated by the oscillator(AG-204, Kenwood, Tokyo). A small speaker $(3 \mathrm{~cm}$ in diameter, Fuji Co., Osaka, Japan) was placed in contact with the surface of the test fruit and a condenser microphone (1.0 cm in diameter, Kaho Wireless Co., Tokyo) was attached to the opposite side (Fig. 1). The speaker and microphone were positioned with two cords, through pulleys and appropriate weights $(58.3 \mathrm{~g})$, to ensure that the speaker and microphone were held in contact with the fruit by equal forces. Sound received by the speaker was amplified by a voltmeter (VT$171 \mathrm{E}$, Kenwood, Tokyo) and the wave was monitored by an oscilloscope (CS-4025, Kenwood, Tokyo). The emitted and received signals were simultaneously displayed on the oscilloscope. The number of waves propagated in fruit tissue was estimated from the phase shift, provided that the actual shift in the number of waves was $<1$ at $200 \mathrm{~Hz}$. The phase shift is a relative measurement of the number of waves in the fruit. If, at $200 \mathrm{~Hz}$, less than one wave is propagated, the number of waves is increased by raising the frequency based on a functional relationship (Fig. 2). But, if one to two waves are propagated in the fruit at 200 $\mathrm{Hz}, \mathrm{l}$ is added to the number.

In some experiments, at a fixed sound frequency, the condenser microphone was gradually moved by hand along the circumference of a fruit toward the speaker. The distance necessary for a $360^{\circ}$ phase shift between emitted and received signals was measured. The physical distance along the fruit directly corresponds to the wavelength of the sound propagated through the tissue.

Principle used formonitoring sound velocity. If the wavelength is $5 \mathrm{~cm}$ at $1000 \mathrm{~Hz}$ and half of circumference of a fruit is $10 \mathrm{~cm}$, this corresponds to two waves along the circumference of the fruit and the sound velocity would be $50 \mathrm{~m} \cdot \mathrm{s}^{-1}\left(=5 \mathrm{~cm} \times 1000 \mathrm{~s}^{-1}\right)$. If the frequency is raised to $2000 \mathrm{~Hz}$ and the sound velocity in the fruit is assumed to be constant, then there would be four waves in the fruit, because the sound velocity $\left(50 \mathrm{~m} \cdot \mathrm{s}^{-1}\right)$ is the product of wavelength $(2.5 \mathrm{~cm})$ and frequency (2000 Hz) (Fig. 2). If the fruit transmits sound at the same speed at various frequencies, the number of waves in the fruit should be proportional to frequency. However, if the sound velocity is changed by the tissue, the relationship between the number of waves and frequency also changes. Therefore, one can monitor the apparent sound velocity propagated in a fruit without measuring the absolute sound velocity.

\section{Results}

When the speaker was directly placed on the fruit, the sound could not be detected. Propagated sound could only be effectively received by the microphone when a small amount of clay was installed between the surface of fruit and the speaker. The sine wave was effectively perceived up to 2000 $\mathrm{Hz}$, but the intensity of the signal fell below the detection limit when the frequency was over $2000 \mathrm{~Hz}$. 


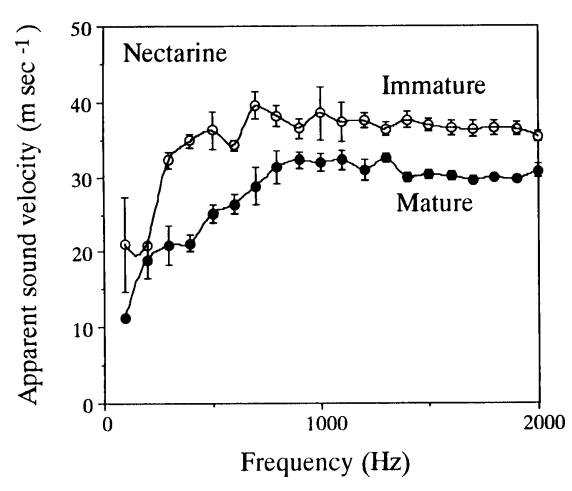

Fig. 4. Apparent sound velocity in mature and immature nectarine fruit. Using wavelength and frequency of the sound, sound velocity was calculated by: Apparent sound velocity = wavelength $\times$ frequency. Data are means, and standard errors are shown $(n=4)$.

A force of $\approx 50 \mathrm{~g}$ was suitable to ensure contact between the microphone and the sample. Forces of $>100 \mathrm{~g}$ caused depression in soft and mature samples and when the force was $<20 \mathrm{~g}$, the microphone did not make sufficient contact. Although the pressure between microphone and sample was kept constant, the amplitude of the received sound did vary between samples, because of uneven fruit surfaces. Thus, the phase shift provided a more reliable measurement than amplitude.

When the microphone was displaced along the surface of a fruit, the extent of the phase shift was directly proportional to the position of the microphone. Thus, it appears that the sound travels along the surface of fruit. The distance necessary to shift the wave one cycle in an immature nectarine was $3.4 \mathrm{~cm}$ at 1000 $\mathrm{Hz}$ and $1.8 \mathrm{~cm}$ at $2000 \mathrm{~Hz}$. These direct measurements of wavelength show that the velocity of sound at $1000 \mathrm{~Hz}$ frequency was $34 \mathrm{~m} \cdot \mathrm{s}^{-1}$ and $36 \mathrm{~m} \cdot \mathrm{s}^{-1}$ at $2000 \mathrm{~Hz}$. Since half the circumference of the fruit was $11.2 \mathrm{~cm}$ and the sound velocity is the product of sound frequency and wavelength, the number of waves in the fruit was calculated at 3.3 at $1000 \mathrm{~Hz}$ and 6.2 at $2000 \mathrm{~Hz}$.

The relationship between the number of waves and frequency in immature and mature nectarine was nearly linear (Fig. 3). Usually about six waves were produced in a mature nectarine and five in immature fruit at 2000 $\mathrm{Hz}$. The mature fruit yielded a higher number of waves than did immature fruit in the range of 200 to $800 \mathrm{~Hz}$ and above $1100 \mathrm{~Hz}$.

The mean of the half circumference was relatively constant in mature and immature fruit at $11.3 \pm 0.1 \mathrm{~cm}$, and $11.3 \pm 0.2 \mathrm{~cm}$, respectively. Using these distances for sound travel, we calculated the sound velocity of mature and immature nectarines (Fig. 4). The velocity in both ripening stages increased as a function of frequency.

Patterns similar to that for nectarine were also observed in apricot (Fig. 5) and plum (Fig. 6) fruit. There was little difference between mature and immature fruit up to $500-600 \mathrm{~Hz}$, but the mature fruit yielded a higher number of

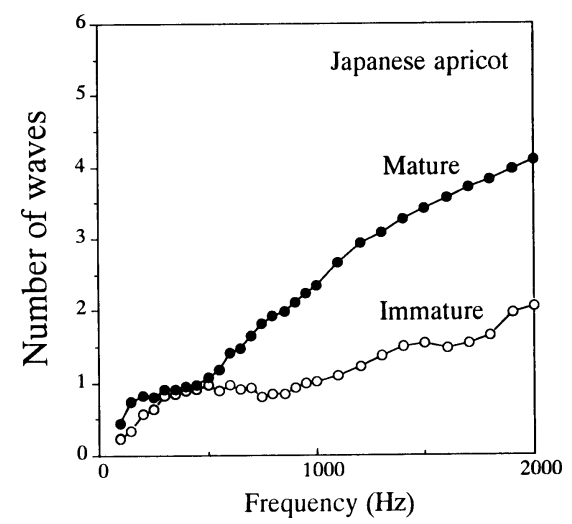

Fig. 5. Relationship between number of waves and sound frequency in mature and immature Japanese apricot.

waves above $600 \mathrm{~Hz}$ than the immature fruit. Unlike nectarine, but resembling the responses of other stone fruit, there was little difference in the number of waves between immature and mature tomato fruit up to 400 $\mathrm{Hz}$ (Fig. 7), but the difference in wave count was prominent above $500 \mathrm{~Hz}$.

\section{Discussion}

The acoustic data derived from these experiments clearly demonstrate that, for the fruit evaluated, the number of waves in the audible frequency range is always higher in mature than in immature stages. Hence, we conclude that a lower sound velocity is propagated in mature fruit than in immature fruit.

The intensity of sound at frequencies higher than $2000 \mathrm{~Hz}$ fell below the sensitivity of the microphone used in our system. Fruit and vegetables previously evaluated by an ultrasonic method gave an attenuation coefficient of transmitted sound that was extremely high (Mizrach et al., 1989; Sarker and Wolfe, 1983). Thus, our results support the concept that an acoustic method with audible frequency (from 200 to $2000 \mathrm{~Hz}$ ) may be practical for evaluation of fruit texture.

Zebrowski (1992) measured the transit time for sound through the leaf sheath of triticale, and calculated the elastic modulus from: Elastic modulus $=$ density $\times(\text { sound velocity })^{2}$

However, fruit samples are three-dimensional; thus this equation is not directly applicable. Nevertheless, since our data revealed that sound velocity was lower in mature than in immature fruit, the decrease in the velocity is likely to be related to a decrease in the elastic modulus.

Previous reports on the ultrasound velocity propagated through fruits and vegetables were similar to what we found. Mizrach et al. (1994) measured the velocity of ultrasound at 50,000 $\mathrm{Hz}$ in melons (Cucumis melo L., 'Galia'); the velocities ranged from 60 to $80 \mathrm{~m} \cdot \mathrm{s}^{-1}$. Self et al. (1994) showed that ultrasound velocity of avocado flesh ranged from 200 to $350 \mathrm{~m} \cdot \mathrm{s}^{-1}$. Here we report that sound velocity of nectar-

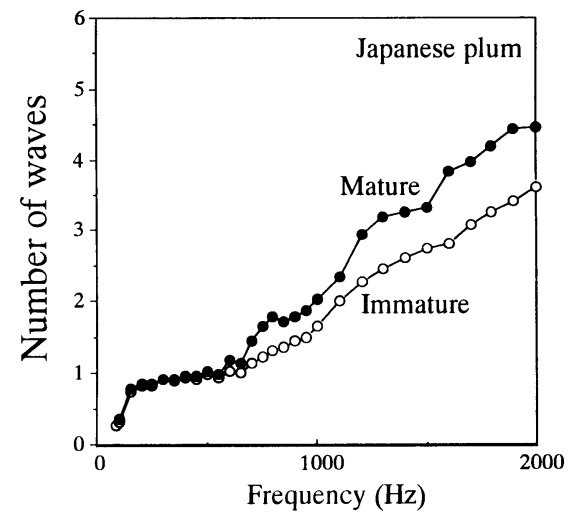

Fig. 6. Relationship between number of waves and sound frequency in mature and immature Japanese plum.

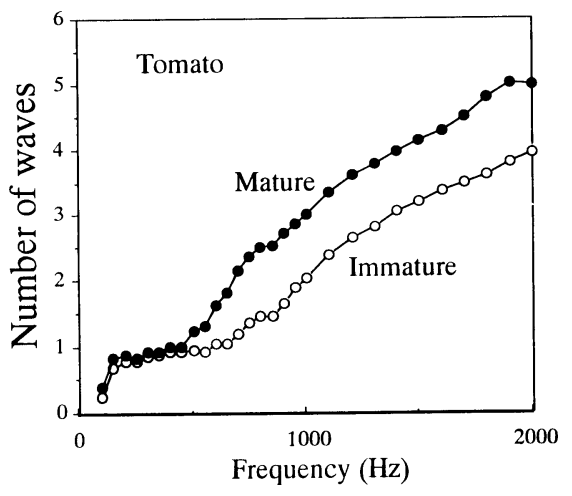

Fig. 7. Relationship between number of waves and sound frequency in mature and immature tomato fruit.

ine was from 30 to $40 \mathrm{~m} \cdot \mathrm{s}^{-1}$ at 1000 to $2000 \mathrm{~Hz}$. The differences in sound velocity reported by these studies many result from effects of tissue structure and impulse frequency.

Justification for the assumption that sound is propagated just under the surface of fruit is supported by the observation that the degree of phase shift was directly proportional to the distance through which the microphone was moved. Acoustics theory prescribes three types of waves that occur during vibration: longitudinal (compression), shear (transverse), and surface (Rayleigh or Love) waves. Our preliminary results, based on analysis by holography, confirmed that $1000 \mathrm{~Hz}$ sound is propagated near the surface of fruit (unpublished data). Therefore, the signal received by the microphone is likely ascribed to a Rayleigh or Love wave.

We recognize that determination of the amplitude of propagated sound through fruit, or, more strictly, the attenuation of sound, affords another useful parameter, i.e., a sound absorption coefficient that is directly related to viscosity. Our attempt to reliably measure the attenuation of propagated sound was, however, unsuccessful, since consistent attachment of the microphone or speaker to fruit 
surfaces was difficult to achieve. Only a slight displacement of the microphone or speaker caused a tremendous change in sound amplitude. As a result we were unable to achieve a reliable determination of sound amplitude in our experiments.

\section{Literature Cited}

Abbott, J.A., H.A. Affeldt, and L.A. Liljedahl. 1992 Firmness measurement of stored 'delicious' apples by sensory method, Magness-Taylor, and sonic propagation. J. Amer. Soc. Hort. Sci. 117:590-595.

Abbott, J.A. 1994. Firmness measurement of freshly harvested 'Delicious apple' by sensory method, sonic transmission, Magness-Taylor, and compression. J. Amer. Soc. Hort. Sci. 119:510-515.

Armstrong, P.R., H.R. Zapp, and G.K. Brown. 1989. Impulsive excitation of vibration in apples for firmness determination. ASAE Paper 89:30523079.

Chen, J.Y., M. Miyazato, E. Ishiguro, and N. Nanba. 1993. Detection of firmness in intact pumpkins and Sakurajima radishes by impact forces. J. Japan. Soc. Hort. Sci. 61: 951-956.

Cooke, J.R. 1972. An interpretation of the resonant behavior of intact fruits and vegetables. Trans. of ASAE. 156:1075-1080.

Cosgrove, D. 1986. Biophysical control of plant cell growth. Annu. Rev. Plant Physiol. 37:377-405.

De Baerdemaeker, J. 1989. The use of mechanical resonance measurements to determine fruit texture. Acta Hort. 258: 331-339.

Falk, S., C.H. Hertz, and H.I. Virgin. 1958. On the relation between turgor pressure and tissue rigidity. Physiol. Plant. 11:802-817.

Finney, E.E. 1970. Mechanical resonance within Red Delicious apples and its relation to fruit texture. Trans. of ASAE. 13:177-180.

Garrett, R.E. and R.B. Furry. 1972. Velocity of sonic pulses in apples. Trans. of ASAE. 15:770774.

Kojima, K., N. Sakurai, S. Kuraishi, R. Yamamoto, and D. J. Nevins. 1991. Novel technique for measuring tissue firmness within tomato (Lycopersicon esculentum Mill.) fruit. Plant Physiol. 96:545-550.

Kojima, K., N. Sakurai, S. Kuraishi, R. Yamamoto, and A. Inaba. 1992. Physical measurement of firmness of banana fruit pulp: Determination of optimum conditions for measurement. Postharvest Biol. \& Technol. 2:41-49.

Kojima, K., N. Sakurai, and S. Kuraishi. 1994. Fruit softening in banana: Correlation among stressrelaxation parameters, cell wall components and starch during ripening. Physiol. Plant. 90:772778.

Krautkramer, J. and H. Krautkramer. 1977. Ultrasonic testing of materials. Springer-Verlag, Berlin.

Magness, J.R. and G.F. Taylor. 1925. An improved type of pressure tester for the determination of fruit maturity. U.S. Dept. Agr. Circ. 350.

Mizrach, A., N. Galili, and G. Rosenhouse. 1989. Determination of fruit and vegetable properties by ultrasonic excitation. Trans of ASAE. 32:2053-2058.

Mizrach, A., N. Galili, D.C. Teitel, and G. Rosenhouse. 1994. Ultrasonic evaluation of some ripening parameters of autumn and winter-grown 'Galia' melons. Scientia Hort. 56:291-297.

Nybom, N. 1962. A new principle for measuring firmness of fruits. Hort. Res. 2:1-8.

Sakurai, N. 1991. Cell wall functions in growth and development. Bot. Mag. Tokyo 104:235-251.

Sakurai, N. and D.J. Nevins. 1992. Evaluation of stress-relaxation in fruit tissue. HortTechnology 2:398-402.

Sakurai, N. and D.J. Nevins. 1993. Changes in physical properties and cell wall polysaccharides of tomato (Lycopersicon esculentum Mill.) pericarp tissues. Physiol. Plant. 89:681-686.

Sarker, N. and R.R. Wolfe. 1983. Potential of ultrasonic measurement in food quality evaluation. Trans of ASAE. 26:624-629.

Self, G.K., E. Ordozgoti, M.J.W. Povey, and H. Wainwright. 1994. Ultrasonic evaluation of ripening avocado flesh. Postharvest Biol. \& Technol. 4:111-116.

Yamamoto, H. and S. Haginuma. 1984a. Estimation of the dynamic Young's modulus of apple flesh from the natural frequency of an intact apple. Rpt. Natl. Food Res. Inst. 44:20-25.

Yamamoto, H. and S. Haginuma. 1984b. Dynamic viscoelastic properties and acoustic properties of watermelons. Rpt. Natl. Food Res. Inst. 44:30 35

Yamamoto, H. and S. Haginuma. 1984c. Dynamic viscoelastic properties and acoustic properties of Japanese radish (Shogoin) roots. Rpt. Natl. Food Res. Inst. 44:36-44.

Zebrowski, J. 1992. Complementary patterns of stiffness in stem and leaf sheaths of Triticale. Planta 187:301-305. 